\title{
Embodied Cognition and Language Appropriation: Recycling with Difference by a Child with Congenital Deafblindness and Multiple Disability
}

\author{
Kirsten Costain, Jacques Souriau, Marlene Daelman
}

\begin{abstract}
This article uses microanalysis of a video case example of embodied cognition and language appropriation in a child with congenital deafblindness and multiple disability. The creative and generative nature of the child's expressions are highlighted in this analysis in an exploration of the dialogical concept of recycling (Linell, 2010), in particular recycling with difference (Anward, 2004; 2014). The central notion of simulation in cognition is challenged here by highlighting the status of the child's expressions as re-workings rather than representations or copies of the original interaction. The account of the micro-analysis of alignment in the case is linked to the cognitive-linguistic perspective of dialogic syntax with its key notions of parallelism, resonance and engagement.
\end{abstract}

\section{Keywords}

Embodied cognition, recycling, dialogical, representation. 


\section{Introduction}

This article presents a qualitative, exemplary case study (Markova, 2006) of embodied cognition in a child with congenital deafblindness and multiple disability. We begin with a critical examination of the central concept of simulation in cognition and perception and contrast this with a radical, enactive view of embodied cognition (Gallagher, 2005; 2011). The case example shows a child who, when left alone briefly, appears to revisit the previous interaction with his teacher in making a series of expressions that seem to reflect aspects of this interaction. Through sequential microanalysis of the entire film clip (2:22), the argument is made that the child's expressions are not mere representations or copies (in the sense of simulation) but rather creative re-workings (recycling) of the original episode (doing up the zipper). Sequential microanalysis using coding processes of grounded theory (Strauss and Corbin, 2015) is used to trace the possible origins of the expressions in the recycling sequence in the bodily-tactile and 'conversational' frames of the interaction between teacher and child.

The linguistic qualities of the child's expressions appear in his successive recyclings of a frame and several elements with variations that are novel (not seen in the original interaction) in addition to entirely new constructions. The dialogical concept of 'recycling' (Linell, 2010), particularly in terms of recycling with difference (Anward, 2004; 2014; Derrida, 1981 ) is employed in the article to further understand the cognitive and linguistic significance of the example. Finally, the resulting analysis is connected briefly to the cognitive-linguistic perspective of dialogic syntax with its key notions of parallelism, resonance and engagement to indicate a relatively new and potentially highly useful direction for further research on embodiment, cognition and communication, both with regard to congenital deafblindness and generally within the fields of cognition and linguistics.

\section{"Simulationist" Accounts of Cognition}

Most theories of cognition regard knowledge as located within modular semantic systems separate from modality-specific systems for perception, action and emotion, and view conceptual representations as amodal, such that states in the modality-specific systems do not have the status of knowledge before they have been re-described in amodal representational languages (Barsalou, Simmons, Barbey, \& Wilson, 2003). The core notion within the modern literature on cognition within psychology, that cognition involves a bridging process of simulation from the modality specific systems to amodal knowledge, originates in the 1940s, was more intensively pursued in the 1960s (Arbib, 2008) and remains central to most computational (mainstream) accounts of cognition today (Gallagher, 2011). Arbib (2008) points out the 3 most relevant definitions of simulation (from the Oxford English Dictionary) with regard to cognition as: unconscious imitation, a false assumption or 
display in terms of an imitation of something, or "the technique of imitating a situation or process (...) by means of a suitably analogous situation or apparatus" (p. 7).

Kaschak and Glenberg (2000) describe abstract thought as achieved through 3 main processes: 1. The metaphorical extension of image schemas to abstract domains ('up' = 'good' and 'down' = 'bad' for example) (Johnson, 1987); 2. The perceptual simulation process of Barsalou (1999) described below; and 3.The understanding of abstract ideas through concrete examples ('containment' understood through actual experience of many different types of containers, for example). In Barsalou's (1999) perceptual simulation account for the development of abstract thought, simulation of a situation is often 'prompted' by language. The resulting simulation makes use of perceptual (analog) symbols that are compared with an actual scene being perceived. The language is then 'judged' as correct when this simulation matches the perceived situation and the concept of truth is emergent as a conscious application of this procedure. Understanding abstract ideas thus arises from concrete experience.

Comprehending and categorizing "novelty" or newness within this concrete experience is both a problem for perception and a means of expanding knowledge. Embodied agents, through interaction with the environment, generate the necessary sensory stimulation to perform proper categorization and through sensory-motor coordination, simplify the problem of mapping this stimulation onto perceptual categories (Hoffman \& Pfeifer, 2011). The notion that the real world plays a role in perception and cognition is part of the concept of cognitive extension, introduced initially by Clark and Chalmers (1998). They proposed that cognition spreads beyond the brain to other parts of the body and to the world (through tools such as pen and paper, and laptops). Connected to this is the Parity Principle (Clark \& Chalmers, 1998) which holds that an extended process is cognitive if it is functionally equivalent to a brain (intracranial) process. Thus, if something in the world functions as a process which, if performed in the head, would automatically be recognized as part of a cognitive process, then that part of the world is participant in cognition (Clark \& Chalmers, 1998). Arbib (2008) places the 'parity requirement' for language at center stage, but notes that the primary function of language is communication. Moving from parity to the further evolution of cognitive capacities such as anticipation, working memory and autobiographical memory (p. 45), he contrasts the poor imitative ability of monkeys and apes with the human ability to "understand any sentence of an open-ended set as it is heard, and generate another, novel sentence as an appropriate reply" (p. 5). One caveat here is that imitation - and simulation - is not the same thing as 'generating novelty'; the dialogical notion of recycling described below (Linell, 2010) and illustrated in the case example is closer to this latter, crucial ability. 


\section{The Radical, Enactive View of Embodied Cognition}

Our perceptuo-cognitive act is borne by the modalities in use at the time or that are available for use, and is often multi-modal (Aziz-Zadeh \& Damasio, 2008). However, the radical enactive view of embodied cognition holds that there is no 'extra', a-modal mental mechanism or process at work in simulation of this perception in order for it to become cognition (Gallagher, 2005). Accordingly, elaboration of knowledge and learning involve taking one's knowledge further rather than simply reproducing it. The enactive, radical view of embodied cognition espoused by Gallagher $(2005,2011)$ and by Thompson \& Varela (2001) is strongly pragmatic in relation to cognition: cognition is, and is for, action. In this approach, cognition is distributed across brain, body and environment, but in contrast to the functionalist view, the contributions of the body to consciousness and cognition are "irreducible and irreplaceable" (Gallagher, 2011, p. 66). In this perspective, perception and cognition are enactive: dynamic systems theory is applied to understand the complex interrelationships of brain, body and environment and there is rejection of traditional notions of representation and computation. There is also rejection of the tendency to "decompose" the cognitive system into modules and sub-systems rather than into dynamic systems that "cut across the brain-body-world divisions" (Thompson \& Varela, 2001: p. 418; Gallagher, 2011, p. 66).

Both Thompson and Varela (2001) and Gallagher (2005) add the dimension of intersubjective interaction to embodied cognition. At the level of neural activity, cognitive processes participate in three types of "cycles of operation" that make up the life of the individual. These are organismic regulation of the body itself, sensorimotor coupling between the organism and the environment and "intersubjective interaction, involving the recognition of the intentional meaning of actions and linguistic communication (in humans)" (Thompson \& Varela, 2001, p. 424). Gallagher (2005) emphasizes the reality of cognition as the following of the intentions of the other (referring to research on the neural mirror system and neonates, as well as Trevarthen's research on primary intersubjective processes (1979)). Perception/cognition-for-action is the "enactive social perception of motor intentions and response preparation rather than a simulation or simple mirroring of mental states" (Gallagher, 2011, p. 67). In this view, perception is primarily for inter-action with others and as such becomes a principle of social cognition and meaning generation. Thus, our interpretation of others' actions is usually at a pragmatic, intentional level rather than an abstract level, based on theoretical interpretation of their bodily-muscular movement or their belief systems. This perspective supports a claim for situated interaction theory within theories of development over the claims often made for 'theory of mind' perspectives (Gallagher, 2005, p. 230). In addition, intersubjective engagement is defined as the ability to engage with the stance or emotional-psychological attitude of the other, to align with or contradict this stance or to respond to it in some way (Du Bois, Hobson \& Hobson, 2014). This 
engagement cannot adequately be described by a "theory-theory" (Gallagher, 2005) approach that excludes affective and motivational dimensions of the person in a narrow definition of cognitive or conceptual abilities (Du Bois, Hobson \& Hobson, 2014).

\section{A Pragmatic View of Cognition and Communication}

A pragmatic focus on intention connected to cognition as action such as that discussed above also fits well with the pragmatic dialogical approach to language outlined by Linell (2009): that it is for communication. Dialogism stresses that there is an action basis to sense making and signifying (p. 238), and in this view, thoughts are action-based processes in which the thinker relates to some aspect of the social context (often other 'thoughts'). In a monological view, a 'thought' is a representation of some 'thing', and intentions are "thoughts and goals that individuals 'have in mind' and express" (Linell, 2009, p. 239). This dominant status of thoughts and the conscious nature of intentions is not shared by the pragmatic view of dialogism, and Linell (2009) reviews four qualifications with regard to the pragmatic definition of the notion of intention. First, ideas and assumptions are strongly social experience-based. Second, some aspects of linguistic and other action are highly routinized and do not require conscious planning. Third, utterances contain the potential for multiple and varied interpretations, both within and beyond the situation of use; and fourth, an utterance is always other-oriented at a general level, with responsive and anticipatory relations, and "(is stretched) out, is turned, directed or intended, to the other's prior and possible next actions" (Linell, 2009, pp. 239-240).

Central to the pragmatism of Linell's dialogical view of communication is the notion of the communicative project (Linell, 2009). A communicative project is a "task carried out (among other tasks) by participants in and through their interaction (acts and activities)" (p. 190). It requires at least two participants, is dynamic through following a course of action, is focused on topics and actions of concern to the participants, and where participants are to some extent engaged in directing their contributions to the other participant(s)' responses (pp. 189-190). The communicative project is concerned with specifying the focus of actions and interactions and in this way, with establishing inter-subjectivity (Linell, 2009). A communicative project can also be participated in with an 'inner alter' (Markova, 2006), in terms of an inner dialogue (Linell, 2009); in this sense, it can be posited that the communicative project is concerned with establishing intra-subjectivity. Such projects can be analyzed in terms of the distribution of communicative labor: who initiates them, who is the main speaker/actor in the body of an activity and who is the addressee, as well as other participants who are not addressees, and other third parties, such as artifacts (Linell, 2010). 


\section{The Dialogical Notion of Recycling: Abstract Thought, 'Novelty' and the Extension of Knowledge}

Abstract thought requires elaboration and this connects it to metaphor (Gallese \& Lakoff, 2005; Aziz-Zadeh \& Damasio, 2008) and to affordances (Kaschak \& Glenberg, 2000). The simulationist account of cognition in all its variations has difficulty describing how novelty that which is unknown and original - can enter the cognitive equation, as by definition it relies on the notion of repetition and truth operations performed based on representation. The notion of recycling understood in the sense of dialogical grammar (Linell, 2002, Du bois, 2010) describes a much more dynamic process of scaffolded discovery and construction that can account for novelty and the extension of knowledge. In this dialogical perspective, meaning is relational and emerges from our dealings with the world; sense-making is achieved through conversation; speakers respond to the communicative requirements of the situation; and what is said at one stage must be seen in relation to what has been said before - resources are exchanged and substituted by other resources in 'recycling with variation' (Linell, 2010; Anward, 2004).

The process of producing something new from previously used materials is one of the common understandings of the term 'recycling'. Recycling in conversation is an action, and the "strategic" use of prior linguistic material for purposes of communication (Perkins, 2014, p. 590). This use of prior material as resource points to the imperative of the project focus (Linell's 'communicative projects' above), of goals and intentions and the pragmatics of interaction (Gallagher, 2005; Arbib, 2008, Glenberg, 2008), also interaction with oneself in terms of the 'inner alter' (Markova, 2006). This focus on recycling as strategic action rather than mere repetition or representation is highlighted in the understanding of language as appropriated rather than acquired (Dufva, Aro \& Suni, 2014). All language use involves recycling community resources, and language learning is the appropriation of these resources, in the turning of them into affordances through active use by language learners (Suni, 2008; 2007, Van Lier, 2007 cited in Dufva, Aro \& Suni, 2014).

Recycling can be viewed as the production of novelty on the basis of the same $\leftarrow \rightarrow$ different dichotomy, exploring what happened/ what I perceived and what is connected, but also different (leading to production of novel aspects of the reconstruction that make it recycling rather than imitation). Arbib (2008) and Lakoff \& Johnson (1980) point out that metaphor as a core means of extending knowledge relies on the appreciation of difference as much as shared or common features. Similarly, Linell (2009) reviews Bakhtin's notions of alterity, and the disruptive-productive influences of the other. The tension produced by the other produces a need for the speaker to orient and re-orient, distinguish and categorize (pp. 
82-85). The tension described here, arguably, is the tension of differance (Derrida, 1981'1) and is a driving force in communication and the extension of conceptual knowledge.

\section{Recycling with 'Differance'/Variation in the Exemplary Case: Embodied Cognition and Recycling by a Child with Congenital Deafblindness and Multiple Disability}

Brief description of the exemplary case. $M$ is a deafblind boy of 12 years with EyeMuscle-Brain Syndrome, completely blind, and with residual hearing. He has not developed formal linguistic communication. He has great difficulty with fine motor movement and can only move his limbs by thrusting them forward and/or upwards. He is capable of "holding" a movement for 2-3 seconds. He has hypotonic muscles, and can make a grip form with his hands but without power. The film sequence is 02:22 in length and extracted from a longer film of just under 7:00 initially made for a communication group meeting (a meeting of teachers, supervisors and family members, care staff in the child's network) at the school where $\mathrm{M}$ is a student. Another teacher at the school stands and films as $\mathrm{M}$ and his teacher $\mathrm{K}$ (the first author) prepare to go swimming. $\mathrm{M}$ is lying on a changing table as $\mathrm{K}$ undresses him and puts on his bathing suit, a long garment with a zipper. There is a pocket at the top of the suit open on the left side into which the head, or tab of the zipper is to be pushed once it is done up. $\mathrm{M}$ has worn the suit many times and knows about the zipper and its pocket from previous experience. He is left alone on the table when $\mathrm{K}$ walks across the room to collect his chair. During these 17 seconds, $M$ appears to be revisiting the doing-up of the bathing suit zipper as he makes expressions that seem related to this.

Method of analysis: grounded theory coding processes. A written transcript of the film was produced by the first author through many viewings and analyzed according to the coding practices of Grounded theory (Glaser \& Strauss, 1967; Corbin \& Strauss, 2015). These employ three types of coding that gradually move from descriptively "opening-up" empirical material or data, to more abstract, theoretical coding based on constructed conceptual codes or relevant concepts from existing theory (Corbin \& Strauss, 2015). Through the core process of constant comparison (Glaser \& Strauss, 1967; Corbin \& Strauss, 2015) the emerging theoretical or explanatory framework is continuously "tested" out against the data in a "flipflop" (Glaser \& Strauss, 1967) movement where the researcher's perspective is deliberately shifted from data to conceptual explanation and back again. A kind of "hypothesis-testing" is performed in which the analyst poses questions to the data and the emerging explanatory framework, testing out how well each responds to the other and reflexively challenging the developing conceptual picture. Coding proceeds through levels of abstraction, though all

\footnotetext{
${ }^{1}$ This term and Anward's use of it in recycling with differance is described and discussed later on in the article.
} 
three coding processes are present from the mid-point to the conclusion of the analysis (the "flip-flop" movement is also that between levels of abstraction as well as between data and conceptual labels).

Open, axial and selective coding. The production of the transcript is itself the result of the open coding phase, but also, following grounded theory method, contains elements of axial coding as coding progresses. The goal of open coding is to "break open" raw data (in this case the film clip) to identify as many units of meaning as possible and to name these (Corbin \& Strauss, 2015); each time we try to describe what is happening in any (micro)second of the film, we are engaged in open coding. Some of these coding attempts are located at the descriptive end of the scale of conceptual abstraction ("M lifts RT back of hand and places it under his chin"), whereas other codes will contain elements of other theories from the literature or theorized content from methods or practices ('K places M's LFT hand in 'listener' position"). The latter are indicated with the use of single quotation marks in the transcript. The idea is to take the data from "raw" to the first level of abstraction, and to indicate where the next level of abstraction, in the axial coding process, is likely to lead. Axial coding is performed primarily through memo writing (such as notes on 'communicative projects' where details from the transcript are mapped to the concept of the communicative project, for example). It is "axial" because the attempt is to link open codes that seem to have a conceptual and theoretical (explanatory) relationship with one another together, and to pursue the analysis along more abstract lines according to theoretical concepts. These may be 'in vivo' - in the material itself as seen through one's analytical gaze - or from the literature/other theories ('source-path-goal', 'communicative project', 'recycling', for example; these and other terms are defined further on in the article).

Memo writing in axial coding is the second level of abstraction. The writing of the analysis section of the study presentation is the third level, selective coding. Groups of codes have then become 'categories' articulated in an explanatory framework (the "theory"). The idea is not that the theory produced is a new stand-alone theory. Rather, the goal is to construct a wellgrounded explanation of what is going on in the case, articulated through the application of concepts the relevance of which is constantly 'tested' in the discipline of constant comparison with the data itself. The presentation of the analysis provided here is a discursive one that also reflects the results of the memo writing referred to above. Description is also (and always) interpretation, and the analytic progress to identification of the central phenomenon of rhematic analysis (rhemes signaled usually by content or keywords are parts of a conversational turn that develop a theme) is part of the "results" as a whole (not mere description of a technical pre-step). Additional confirmation and specification of the results was obtained by coding the recycling sequences of the film with the help of the computer qualitative analysis program N-Vivo. The identified codes with timings were listed as nodes and re-identified in the film, which enabled more specific timings and crosscheck of 
interpretation of the rhematic expressions (expressions made within a recycled frame that are related to the development of a theme) with a colleague consultant in the field of congenital deafblindness. Screen shots of the expressions are presented here with commentary.

\section{Analytical procedure.}

Part 1 of the analysis. The transcript of the film was divided into sequences with interpretive comments. Within each sequence, there was a central 'topic' or theme (such as taking off or putting on, preparing for the next action and so forth). This was identified using a general narrative structure for each sequence of a beginning, a middle, and the point at which the interaction changes and a new interaction sequence begins (this division into sequences is in itself an interpretive-analytical move). The interpretive reading of each sequence appears in shaded grey text to distinguish it from the more purely descriptive account of the transcription itself. Details connected to the identification of the rhematic expressions described in part 3 of the analysis are highlighted with red asterisks ${ }^{*}$ ).

Part 2 of the analysis. Communicative project: alignment/non-alignment ${ }^{2}$. Here the interpretive focus is on the project of alignment (defined in terms of 'agenda' management) between the interacting parties, $\mathrm{M}$ and $\mathrm{K}$, in the conversational frame of their interaction.

Example of the analysis, Parts 1and 2: description of sequences with interpretation - the communicative project of alignment and 'agenda' management

\section{Sequence 1: 00:06 - 00:14}

$\mathrm{M}$ and $\mathrm{K}$ getting $\mathrm{M}$ changed to go swimming. $\mathrm{K}$ is taking off M's tops.

00:06: (M kicks bar of table with RT leg audibly; not shown on film)

00:07 - 08: Head movement to Rt held to 00:11

00:07: Grasping of bar with Rt hand

00:09: Touches K's leg with RT hand

00:10 - 00:11: Grasps bars partial, then fully - slides hand up to 00:12 (00:11 head from Rt - Lft)

00:13: resisting releasing sleeve from grasp Lft hand

M's intention: exploring/establishing ('framing') physical frame of the rail of the changing table with one hand. M's resistance to release sleeve with his other hand at 00:13 can be viewed as part of this 'framing'/exploring rather than as a challenge to K's changing-clothes agenda when viewed together with other exploring/'framing' action; this resistance may also be an additional action within the topic of challenging-K's-agenda, something $\mathrm{M}$ does repeatedly at specific transitional points throughout by using vocalization and some gestures.

The above activity might be part of a larger project he has with himself to assert his own framing within the frame controlled by K (agenda of changing clothes to go swimming; talking about and doing the

\footnotetext{
${ }^{2}$ Definitions of the concepts mentioned in this description of analytic process are given in full on pages 10-12.
} 
changing) and that presented by the table itself. His actions can be viewed as a challenge to the shared (though heavily skewed regarding control, towards $\mathrm{K}$ ) project of getting ready to go swimming. M's 'impatient' manner vocalizations in later segments indicate his investment in "getting on with" the process of getting ready. His agency (and thus the intentional nature of his activity as action) is suggested by his sustained (whether involving resistance to getting undressed or not) exploring/checking/ establishing of the physical frame.

Based on the above:

00:11 - 00:12: Movement of head and sliding Rt hand up bar can be viewed as M's extension of the frame. 00:13 - 00:14: K is pulling sleeve out of M's grasp and "showing" / modelling coming action Negotiating about pulling arm out of sleeve/moving on can be viewed as part of a larger communicative project of negotiating control of the agenda right now.

Part 3 of the analysis. Identification of the central phenomenon of interest: recycling with differance or variation (Anward, 2004; 2014). On the basis of the analytical-interpretive account given in Parts 1 and 2, and grounded in the interpreted detail presented there, the phenomenon of interest is identified as recycling, and as such, involves an analysis of frames, stance markers and rhemes (Anward, 2004). Related concepts were applied during the selective coding phase of the analytic process, and these are defined below.

Analytical concepts. The analytical coding process resulted in the adoption of specific terms and definitions because of their explanatory power in defining the phenomenon of interest illustrated by the case and expanding knowledge about it. Their identification is thus part of the study results:

Action. is activity that involves intention (not restricted to goal-directed activity, but in the sense suggested by the definition below). It is activity directed toward something, an idea, desire, goal, object, plan, etc. In the pragmatic frame adopted here, perception, cognition and language use are all actions, as well as being for action (Gallagher, 2005; Arbib, 2008; Glenberg, 2008; Linell, 2009). This makes 'action' a human imperative superior to all three.

Intention. The definition of intentionality adopted here is that described by Gallagher and Zahavi (2008) (and based in the phenomenology of Husserl, 2001) in the generic sense of "pointing beyond itself" that is a determining feature of consciousness. They cite Husserl's teacher Brentano's (1874/1973) focus on the Latin root of the word, intendere, to aim in a particular direction). In this definition, intentions and intentionality have to do with "the directedness or of-ness or aboutness of consciousness" (Gallagher \& Zahavi, 2008, pp. 109110).

Source-path-Goal (S-P-G). This refers to one of the cognitive/metaphorical schemata described by Johnson (1987) as an organizing cognitive metaphor for experience that is also developed through embodied experience. In every case of a PATH schema (whenever we move from one place to another we do so following a path), there is a "recurring image- 
schematic pattern with a definite internal structure" (p. 113): 1) a source, or starting point; 2) a goal or endpoint; and 3) a "sequence of contiguous locations connecting the source with the goal". Here it is also a mini frame within the interactional (in the sense given below) frame of getting ready to go swimming. The S-P-G format is a central organizing metaphor for all teaching work at the school (the day begins with a review of the tactile reference 'cards' in linear format detailing the half-day plan, for example, which constructs a "path" through the day).

Interaction: The term is used here in a dialogical (Linell, 2009; Gallagher \& Zahavi, 2008) sense of inter-acts, in which the communicative action is produced by the parties in coconstruction and based in what has gone on before. The source of each action is thus within the inter-action of the parties, not the isolated mental activity of either party. In this perspective, there is no autonomous individual author of any particular action within the interaction.

Recycling: The sense of the term as it is applied here lies very close to its popular usage, as the notion of taking something old or used and making something new and usable out of the old elements (rather than the notion of "running through it all over again" as in 're-cycle', for example). It concerns the use of prior linguistic material for the purpose of communication and reflects the sequential nature of linguistic communication (Perkins, 2014; Linell, 2010). It is creative, in the production of new expressions and of language as a system (Anward, 2004); it is a strategic resource (Anward, 2004; Perkins, 2014) and is a key generative process at the heart of language appropriation (Dufva, Aro \& Suni, 2014). The terms laid out in Anward's (2004) presentation (using Derrida's, 1981 notion) of "recycling with differance" (see under 'Rheme' below) inform the analysis presented here.

Alignment: The 'interactive alignment account' (Pickering \& Garrod, 2004 cited in Perkins, 2014) refers to the necessity for conversational success of the partners' ability to attune to one another and continually make their linguistic productions more similar at all levels (pp. 593-594) and is closely allied with 'priming', or the process through which the production or perception of a particular linguistic form facilitates the subsequent production or comprehension of this, or a similar form (Pickering \& Ferreira, 2008 in Perkins, 2014, p 593). It is closely allied with the notion of stance markers (Dubois \& Giora, 2014; see definition below).

Rheme: A rheme is a turn characterized by keywords or content words pertinent to a topic or theme and that develops this theme. Anward (2004) in his delineation of "recycling with differance" describes rhematic sequences as the element most relevant to topical progression. Derrida's (1981) notion of differance is the sense of difference, "as it unfolds, or is constructed in time" (p. 10 in Anward, 2004, p. 26). In recycling with differance, speakers model new turns on old turns so that the overall format of the old turn is maintained (whether 
implicitly or explicitly) and a new expression substituted for a part of the old turn (Anward, 2014, p. 2). Differance is thus "set into play" with each new recycling of an old turn (p. 2).

Frame: A format or structure within which the conversation / interaction takes place. Such a format as S-P-G presents a way of introducing detail that highlights some aspects while hiding others. In recycling with differance, the overall format is retained, but a new expression is substituted for part of the old turn (Anward, 2004). In such recycling sequences, the speaker must remember "exemplar turns" in their sequential and situational contexts in reproducing this frame; the S-P-G metaphor can be viewed here as such an exemplar turn visible in M's recyclings.

Stance Markers: Simply put, an element of linguistic pragmatics that has to do with ways speakers express (usually through adverbial phrases) their attitude to, evaluation of or allegiance to whatever it is they are saying, including emotions, assessments, intensity and other often difficult to define (linguistically) aspects of speaking (or writing) (Biber \& Finegan, 1989, for example). Berman, Ragnarsdottir and Stromqvist (2002) in their literature review on discursive stance, highlight Ochs' (1996) focus on situated conversational interaction and the means by which children acquire the ability to use language constitutively. They identify four topic areas in the literature with relevance for the analysis below: a) Evaluation, concerning elements of narration relevant to sequencing events and establishing narrative structure; b) Involvement, or the interactive features of discourse, in particular Tannen's (1985) point that conversation is dependent on interpersonal involvement and that this is more important than message or information; c) Perspective, particularly the performative sense promoted by Chafe (1994) in terms of "point of view" (expressing connection to, vs. displacement from, a topic for example), and d) Distancing devices, or "the linguistic means used to express discursive stance along a range of distinctions", such as personal - general, immediate- detached, involved - distanced (Berman, Ragnarsdottir and Stromqvist, 2002, p. 134).

\section{Central Communicative Project in the Film Example: Alignment and 'Agenda' Management}

The notion of 'agendas' in interaction points to the tensions and 'at-stake-ness' inherent in communication. An overarching project $\mathrm{M}$ and $\mathrm{K}$ have concerns construction and negotiation of alignment with the dominant agendas of getting ready/changed to go swimming, teaching (K), and 'hurry up' / 'next thing' (M), in keeping with the conversational (and pedagogical) frame of their interaction. Their generally harmonious interaction is nevertheless characterized by asymmetry with $\mathrm{K}$ dominating the action and thus the agenda management underlying it. $\mathrm{M}$ challenges this hegemony at specific points and $\mathrm{K}$ works to recapture his attention and return them both as interacting agents to her twin agendas of getting changed to go swimming, and talking/teaching about getting changed, including 
engaging $M$ physically (and emotionally) in specific related actions. The frame is one of conversation, with vocal utterances and vocal gestures $(\mathrm{K})$ and vocalization / vocal gestures (M) playing a large part throughout. K positions M's hands in speaker/listener positions ${ }^{3}$, and likewise, positions herself in listener/speaker positions in relation to him. Several times, the speaker position with $\mathrm{M}$ as speaker is constructed by $\mathrm{K}$ into a doer position (his fingers placed and held on the zipper tab, for example).

In the conversational frame constructed by $\mathrm{K}$ are also conventional signs, tactile signs, haptic information, general touch, vocal language, vocalizations and "markers" (such as beats both vocal and physical). The Source-Path-Goal metaphor functions as a mini-frame (K repeatedly marking the source of the zipper, the path along which the zipper runs toward the goal place at the top of the zipper when it is drawn up) within which the other elements are placed. K uses positioning of her own and M's hands to show the connection between speaking-about and doing-of related actions.

While K uses her voice and her hands, M uses vocalization throughout in terms of vocal gestures, volume and forcefulness variation, emotional sounds, 'thinking' clicking sounds (similar to humming while one waits or reflects casually), and moves between vocalization and prolonged periods of quiet. M produces many expressions both vocal and muscularbodily through movement of head, limbs and/or hands.

The highlighted, interpreted detail in each sequence of the transcript suggests $M$ is active, expressive, attentive and aware of several competing intentions simultaneously (hurry up, next thing, now we're doing this, joining $K$, challenging $K$, waiting, listening, commenting). His patterns of vocalization and quiet fit the action (lengthy quiet stillness as he follows $\mathrm{K}$ and his own involvement; vocalizing during transitions/completion of one task and delay before beginning 'next thing'). The intersections of K's and M's vocalizations show points of shared commentary as well as points of conflict when M challenges K's agenda hegemony. M shows interest in and knowledge of the (conversational) frame of the action on the table (including the physical table) as well as making clear expressions in the direction of the next frame, showing his ability to hold competing ideas and intentions in mind at the same time.

\section{Presentation of the Recycling Sequence: Self-addressed Expressions in Recycling with Difference/Variation}

Below is an illustrated account of the recycling sequence followed by an analysis of the construction of alignment and non-alignment in the film. In Sequences $15-22, \mathrm{M}$ is left alone as $\mathrm{K}$ walks to the opposite side of the room to collect his wheelchair, having informed him of this vocally, with signs and with haptic information.

\footnotetext{
${ }^{3}$ In tactile signing 'speaker' position, the speaker has her hands under the hands of the one to whom she is speaking; in 'listener' position, the hands of the listener rest lightly on the hands of the person speaking.
} 
Sequence 15: 01:58 - 02.04

01:58 and 01:59: audible pronounced OUTBREATHS

02:00: breathing in 'pants' with upwards movement in hands, bent elbows

02:01: Beginning of second leg lift gesture - held from 02:02 - 02:03

02:04: M moves head to Rt as $\mathrm{K}$ says something from across room

Second deictic point with foot and raised leg: lifting up from table, moving foot forward; K's comments etc. keep her within communication distance; M's gesture referring to moving on, getting up from table, 'next thing'. Breathing also suggests 'force' metaphor (Johnson, 1987) that M employs in his vocalizations to urge $\mathrm{K}$ to move faster/get to next thing faster.

Sequence 16: 02:05 - 02:06

02:05: M moves fingertips on both hands down towards source place to middle of suit on either side of zipper while making clicking sounds with tongue, then up to top of suit at 02:064

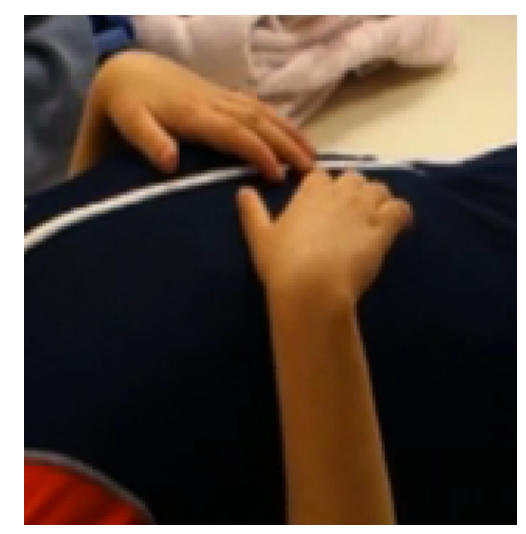

Figure 1. Zipper manner on place

Recycling of 'zipper' manner on place: DOWN towards $\rightarrow$ source, UP to $\rightarrow$ goal

Sequence 17: 02:07 - 02:08

02:07: M moves fingers DOWN to middle of suit "clicking" with movement then UP to top of suit at 02:08 twice, middle fingers of Rt hand slightly 'interwoven' with middle fingers of Lft hand followed by recycling of 'zipper' manner and 'fastening' manner on zipper place

\footnotetext{
4 'On place'_refers variously to a particular point (as in 'source/goal' place) or to a series of points along a trajectory within a particular place (front of the bathing suit, as in 'zipper' manner on place). The point is that the expression has a location or mode of placement (place) as well as a form (hand form) plus movement (which together are manner). I thank Anne Nafstad (personal communication, 2018) for suggesting this descriptive coding, based on her own work. My colleague Gøran Forsgren (2018) has pointed out that handshape, location and movement are identified in the literature on sign language as necessary components for an expression to qualify as a sign.
} 

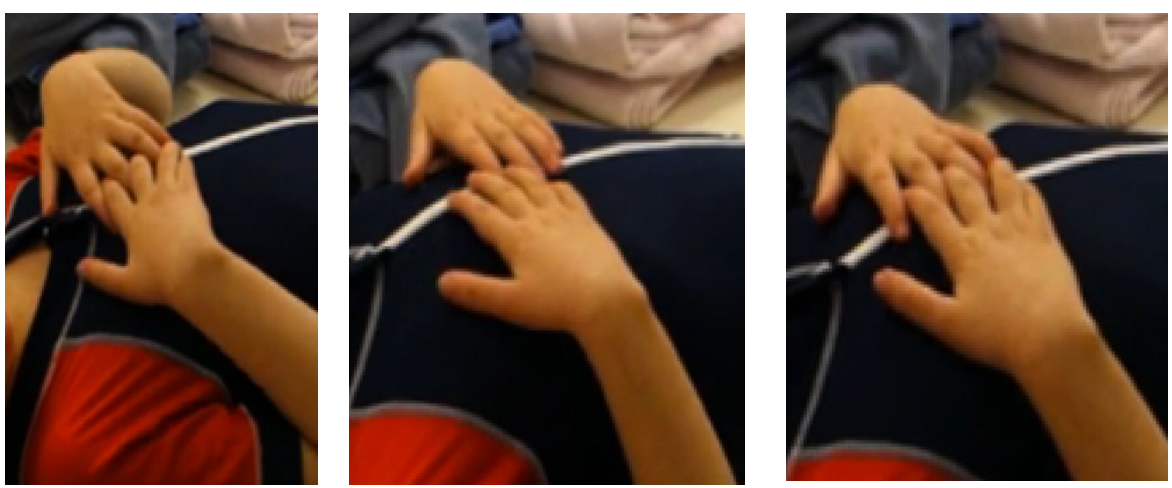

Figure 2. A, B and C 'Partially closed zipper - open neck suit' manner on place (A) and moving down-up (B) $\rightarrow$ to 'closed zipper teeth' manner on place (C)

New rhematic expressions: interwoven fingers = 'Partially closed zipper - open neck suit' manner on place and 'closed zipper teeth' manner on place

Sequence 18: 02:09- 02:10

02:09: Third recycling sequence all the way DOWN to 'source' and back UP to 'goal' on either side of zipper

Recycling $\rightarrow$ path $\rightarrow$ source $\rightarrow$ path $\rightarrow$ goal

while vocalizing with 'clicking' as hands run UP to top of suit and K says "Yes, bathing suit"

Sequence 19: 02:11 - 02:13

02:11: M's Lft hand fingers on zipper at top of suit ('goal') while Rt hand fingers move DOWN over zipper (to 'source') recycling

02:12: Brings fingers of both hands together over zipper at 'source', thumbs almost touching 02:13: fingers/hands moved UP in 'sweeping' motion to 'goal' place

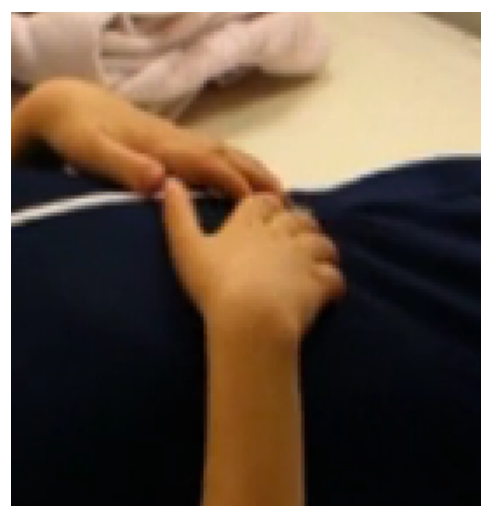

Figure 3. Thumbs almost touching: start of action for $4 \mathrm{~A}, \mathrm{~B}$ and $\mathrm{C}$ 

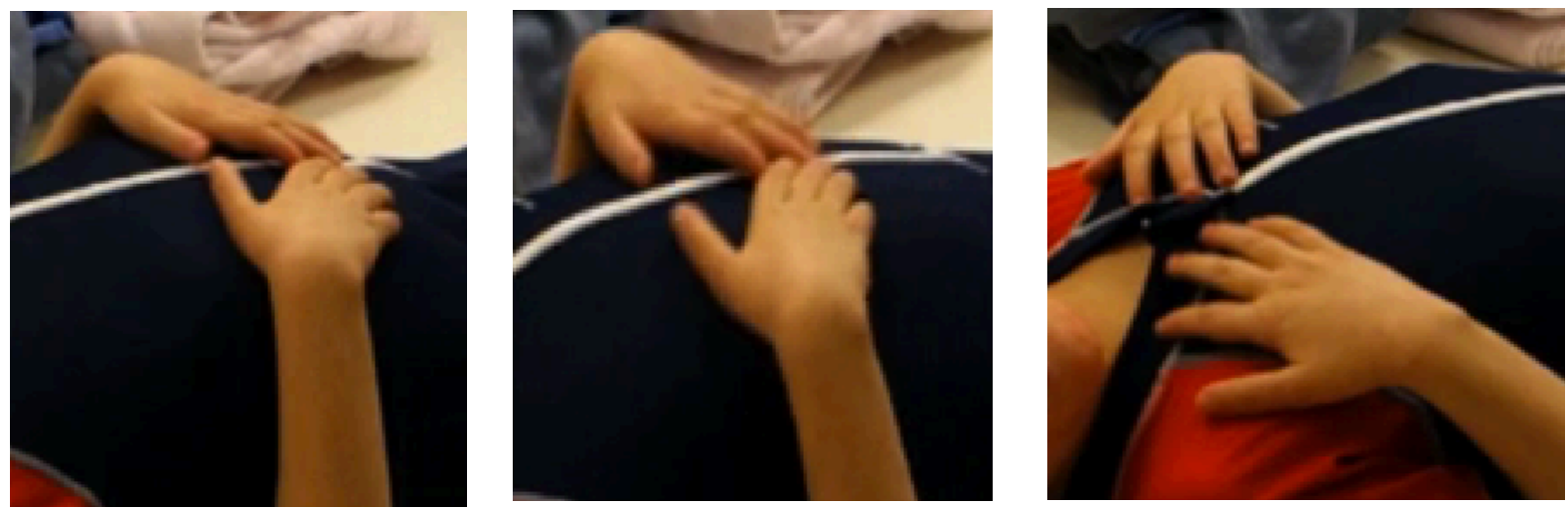

Figure 4. A, B and C 'zipping all the way up' manner: beginning to move UP towards goal at top of suit (A),

$\rightarrow$ middle of suit (B) $\rightarrow$ arriving at goal (C)

recycling 'zipper' manner on place and thumbs touching seems to reflect fastening/'fastened' manner theme. The sweeping motion is novel and summarizes rather than simulates the entire zipping episode (this is not a reproducing of the zipping: the original doing-up was interrupted at 01:24 when the zipper got stuck and not a sweeping motion). Rhematic expression with variation: 'zipping all the way up' manner.

\section{Sequence 20: 02:14}

Moves hands DOWN slightly from 'goal' to upper chest and 'weaves' fingers together over zipper, thumbs pointing towards one another (5A). While 'clicking' brings 'woven' fingers UP to neckline of suit ('goal') (5B).
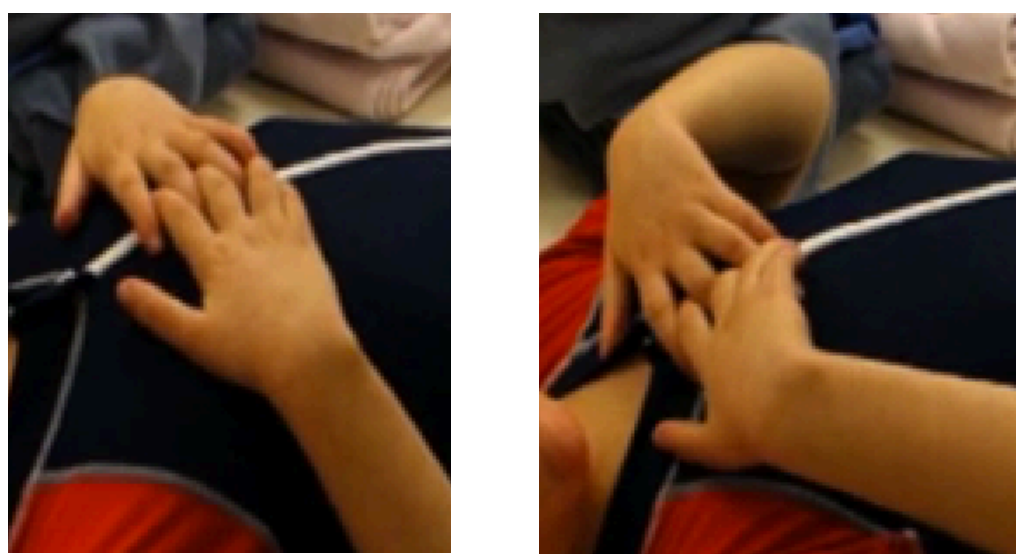

Figure 5. A and B 'closed teeth' with 'zipper' manners on place = 'fastened zipper' manner on place

Recycling 'closed teeth' with 'zipper' manners on place $=$ 'fastened zipper' $\underline{\text { manner on place }}$

Sequence 21: 02:15 - 02:16

02:15: Rt Thumb and forefinger in (non- visible) pincette form with Lft hand held lightly over zipper: 


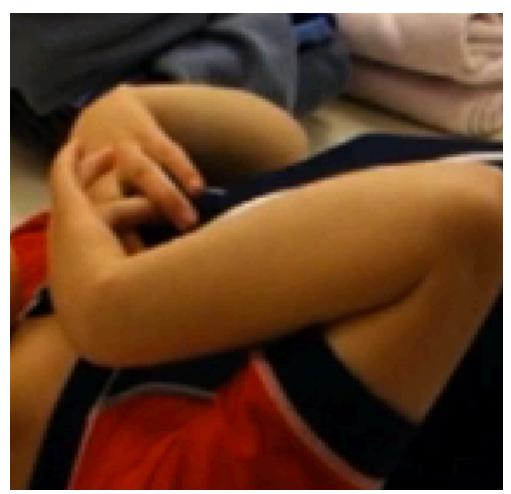

Figure 6. 'Goal' - 'zipper tab' manner on place

new rhematic expression: Recycling 'goal' - 'zipper tab' manner on place; short 'click' sound at 02:15 then beginning of next quiet period (02:15 - 02:28)

02:16: Cupping Rt hand over Lft (switching roles of hands):
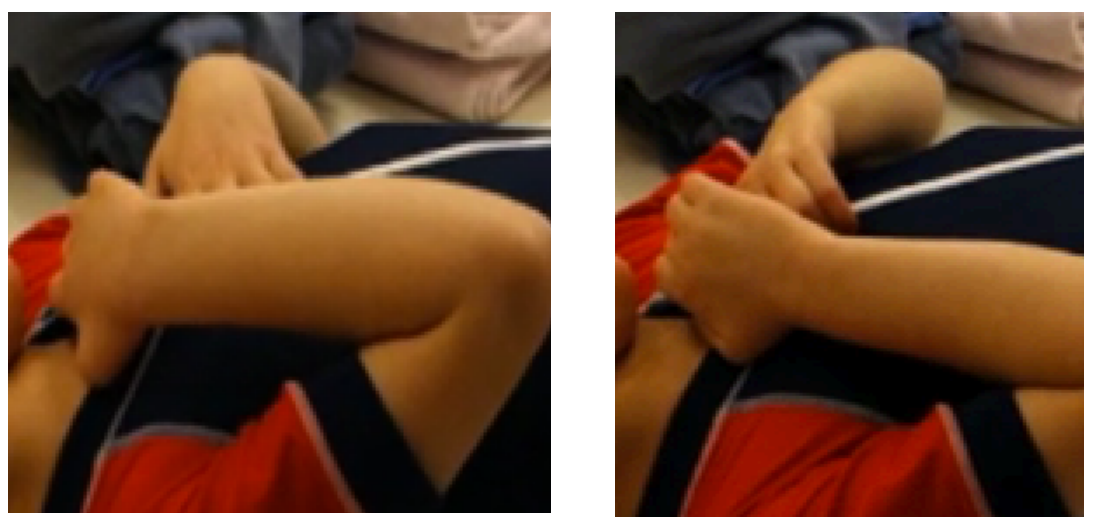

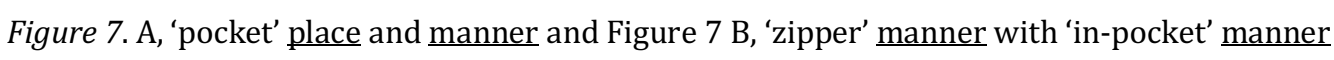
new rhematic expression of 'pocket' place and manner

Sliding Lft hand DOWN $\rightarrow$ UP along zipper place to inside of Rt hand recycling 'zipper' manner with 'inpocket' manner

Sequence 22: 02:17 - 02:22

Last recycling section: pushing left thumb against zipper (recycling K's pushing of tab into pocket) with Rt hand still cupped as it is lifted UP from suit, back of Rt hand brought UP to chin and held with Lft hand also UP to chin
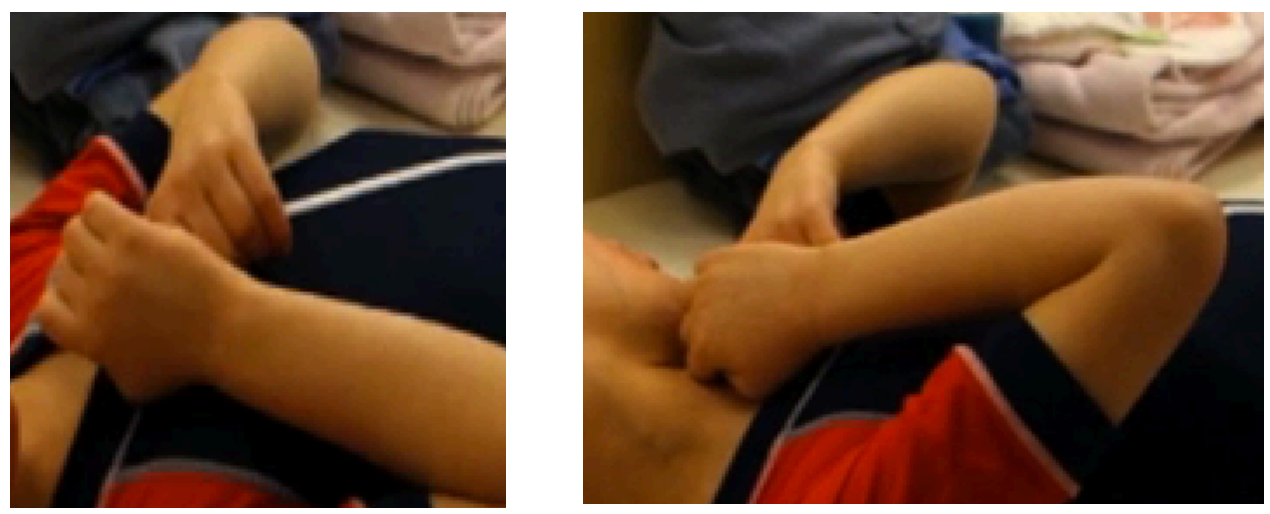

Figure 9. A and B 'goal'/ 'fastening' place and manner and fastened up to here (chin) place and manner 
Recycling 'goal' / 'fastening' place and manner; it is also possible to view this up-to-chin with pressure against chin as a (recycling of ) a BET (Body emotional trace5, Daelman, Nafstad, Rødbroe, Souriau and Visser, 2001) marking the UPness (as in all the way UP) of the 'goal' manner on place/ feeling of M's hand being pressed against his chin as K pulls up the zipper tab to the top 'goal' place. M might also or as part of this be 'measuring' the distance from the zipper-done-all-the-way-up to his own chin. He maintains this last expression for a little over 3 seconds.

M's recycling from sequence 16 - sequence 22 is rich and presents several novel elements as well as recycling elements from his interaction with $\mathrm{K}$. Next, the analysis of alignment and non-alignment between $\mathrm{M}$ and $\mathrm{K}$ is presented to show M's recycling as recycling rather than repetition, simulation or even enactment.

\section{Stance and Stake in the Communicative Interaction: Alignment and (Threatened) Non- alignment with the Dominant Agenda(s)}

In order to understand M's expressions in Sequences 16 - 22 (02:05 - 02:22) as recycling, it is necessary to look at the patterns of alignment in M and K's interaction preceding them. This is because alignment patterns indicate the emotional engagement of the participants with their interaction and with what is at stake for each of them. Engagement is reflected in M's recycling of elements of this interaction. One definition of alignment with relevance to recycling is the 'interactive alignment account' (Pickering \& Garrod, 2004) referred to above that stresses the need for both partners to attune to one another's linguistic constructions and continually strive to "make their own more similar at all linguistic levels". In this cognitivist psychological account, alignment is motivated by underlying cognitive mechanisms and shared mental representations. Another perspective is conversation analytical, emphasizing alignment in terms of utterances that facilitate the other speaker, and "disalignment" in terms of interruption or obstruction of the other speaker's narrative (BarthWeingarten, 2011). Alignment, understood here as patterns of attunement, also linguistic, and in terms of non-alignment/obstruction of interactional flow, is evident throughout the film.

This pattern of alignment and dis- or non-alignment is most clearly seen in the patterns of vocalization and quiet (M) and the overlapping of M's vocalization and K's spoken commentary at specific junctures. It is also shown in the gestural expressions of $\mathrm{M}$ and $\mathrm{K}$, both vocal and muscular-bodily. M challenges K's hegemonic changing-getting ready / teaching agendas with his own 'hurry up' / 'next thing' agenda and K works to manage the threat of his impatience to both her agendas and to the harmony of their interaction.

\footnotetext{
${ }^{5} \mathrm{~A}$ BET is a bodily emotional impression or trace left following an experience that can be seen in gestures produced by the person after the experience is over. The degree of engagement in the experience increases the likelihood of its leaving behind BETs.
} 
One of K's pedagogical goals is engaging M's attention and directly involving him in each step of the process. $\mathrm{M}$ is both concerned with getting to the main goal of their activity (the much-loved activity of swimming) as well as concerned with the pain imposed by boredom when the action becomes uninteresting/takes too long. There are emotional stakes for both of them in terms of the threat non-alignment poses to their separate and shared agendas: they are both interested in going swimming; M's 'impatient' manner sounds are truly disturbing and teaching is more fun when the student is harmoniously listening and following, and something of a trial when this is not the case.

The emotional stakes are likely to be somewhat equal in strength (though for different reasons) for both $\mathrm{M}$ and $\mathrm{K}$. Evidence for this equality (within the nevertheless heavily skewed power relation in K's favor) can be found in the frequent intersections of their exclamatory/ single comment vocalizations. It is also seen in M's 'helping' manner expressions, his quiet, still 'listening' periods, his signs of anticipation and his conditional suspension of pushing his 'next thing' agenda and waiting to see, as well as in the general symmetry of their vocal interaction throughout.

M's recycling of the S-P-G frame indicates the generally high alignment of $\mathrm{M}$ and $\mathrm{K}$ during the talk about and doing of zipping up the bathing suit. As well, the pattern of alignment/nonor challenging alignment shows M's stance in the interaction with $\mathrm{K}$ and the bathing suit zipper. In Sequence $\mathbf{1}^{6}, \mathrm{M}$ is holding onto a sleeve K is trying to take off (00:13), and this act can be read as part of a topic running through the film, of challenging K's agenda / registering impatience. It creates an obstruction at any rate for $\mathrm{K}$ to resolve, which she does by trying to 'show' the coming next step (00:13-00:14). The section of quiet from M at Sequence 2 is prolonged (00:14 - 00:28) and suggests that his attention has indeed been refocused on joining $\mathrm{K}$ in taking off the tops together, additionally supported by his 'helping' manner head lift at 00:19 and raising of both hands up to the neckline of the top at 00:21 directly after K's spoken directive. He remains in the 'helping' manner position until a change occurs at the start of Sequence 3 (00:28) when the action is concluded abruptly by M's head falling on the table ('exclamation' sound from $\mathrm{M}$ at 00:29 as $\mathrm{K}$ also comments vocally).

M's 'raspberry' vocalization followed by his 'quick movement' shaking gesture (00:32 and 00:33) introduce 3 stretches of 'impatient' manner vocalizations beginning at 00:34 and ending at 00:38 before a shift in stance and a prolonged period of silence in Sequence 4 (00:38 - 00:44). His vocalizations from 00:29 until he becomes quiet intersect K's speech and threaten her teaching agenda, highlighting his 'hurry up'/'next thing' agenda.

The Source-Path-Goal frame within the overarching 'conversation' frame. Throughout the film, $\mathrm{K}$ is involved in holding M's attention through all the 'steps' within the whole that is 'getting ready'. She does this by employing a foreshadowing of coming actions

\footnotetext{
${ }^{6}$ As it is not possible here to provide stills of the whole film, descriptions are referenced to sequence number and time locations on the film clip.
} 
showing the start (source), route (path) and endpoint (goal) of specific processes, and by using 'speaking' and 'listening' hands. The use of 'conversation hands' in tactile sign support is a means of taking and assigning conversational roles and by which the interaction is placed within the context of a 'conversation'.

In Sequence 4 (00:38 - 00:44), $\mathrm{M}$ is completely silent and still as K introduces the bathing suit and the source - goal mini-frame (beginning in Sequence 3 at 00:36; Sequence 4 at 00:39, 00:40 - 00:41). At the end of Sequence 3, she returns to the conversational frame with speaking/listening hands (00:36). K reintroduces the changing/ teaching agenda directly by issuing a vocal directive that becomes a question at 00:38. She uses vocal beats at 00:40 00:41 to mark the frame. At Sequence 5 (00:44 - 00:55), M's 'complaining' manner vocalization threatens alignment with the changing and teaching agendas and occurs as $\mathrm{K}$ begins to put his arm into the suit, shifting from speaking about to doing and is a possible comment on the delay caused by K groping after the suit. His leg lift + foot point gesture at Sequence 6 (00:55) further suggests his (literal) raising of the 'hurry up' / 'next thing' agenda indicated by 'complaining' manner. His exclamation in Sequence 7 at 00:58 occurs as K says "There" and is followed by an audible OUTBREATH with another vocalization at 01:00 as K says "There:er:ere".

The conditional suspension of M's 'hurry up' agenda and his move to align with K's changing/getting ready agenda (suggested by the co-occurrence of these expressions with those of K and with the action at 01:01 - 01:05) is then threatened in Sequence 8. M makes 'complaining' manner sounds again at 01:06 -01:07 and vocalizes into the back of his hand (01:08 -01:14). His 'clicking' sounds from 01:13 - 01:17 suggest a shift in stance back to a return (conditional, "I'm not forgetting about "next thing'!") to aligning with the changing agenda (they indicate waiting). His movement of his hand away from his mouth at 01:14 suggests his following of the changing action as Sequence 9 begins (01:15 - 01:16) during which K recycles the S-P-G format of 'zipper' manner, again placing M in 'speaker' position.

Doing up the zipper. In Sequence 10 (01:17 - 01:30) the zipper is being done up with M's fingers held on the zipper tab, and $M$ is quiet. The sequence begins with $M$ in 'listener' and $\mathrm{K}$ in 'speaker' position, with his left hand being spoken into and his right resting at 'goal' place until 01:28. A communicative project of doing up the zipper is begun as $\mathrm{K}$ invites $\mathrm{M}$ to join her at 01:18. She uses a haptic gesture and directly involves $M$ in an assumption of his confirmation at 01:19 - 01:22 as she aligns him physically with the 'changing' agenda, maintained through conversation hands (M's fingers are in "speaker" position and "doer" position at the same time). M prepares to vocalize at 01:23 but there is an obstruction at 01:24 when the zipper becomes stuck. K repositions M's fingers restarting zipping at 01:26, followed by M's vocal gesture of 'zipper' sound manner at 01:27. M's production of this highly salient vocal gesture (also a new gesture) seems directly related to the interaction of both 
partners with the zipper and suggests a moment of high alignment in the communicative project of doing up the zipper. At 01:28, K says "There" to mark the success of the resumed zipping action and marks 'goal' place again at 01:30 as she pokes her index finger into the zipper tab pocket with M's fingers holding around her finger as she does so. Just before this, M's Lft hand has been pressed against his chin as K brings the zipper tab to 'goal' and before she marks the pocket with her finger. M's quiet, still stance, and his tactile following of $\mathrm{K}$ suggests his attention to this action.

In Sequence 11 (01:31 - 01:37) K recycles the bathing suit S-P-G frame as M vocalizes (01:31, 01:32 and 01:34) intersecting her speech at 01:34 and reasserting his 'next thing' / 'hurry up' agenda. She resumes the conversational frame and gives haptic information about moving over to the shower to which M appears to attend. Sequence 12 (01:37 - 01:52) is a period of complete stillness and quiet for $\mathrm{M}$ and involves $\mathrm{K}$ speaking about the next activity of showering. In Sequence 13, M maintains placement of his left hand on, near or around the 'goal' place of the zipper and this seems to reflect his mental focus on this last interaction with $\mathrm{K}$ and the zipper concluded at 01:30. At 01:54, $\mathrm{K}$ leaves after making a tactile and vocal 'contract' with $\mathrm{M}$ to return with $\mathrm{M}$ moving his head in the direction of her leaving at 01:55, indicating his following of her action and suggesting acceptance of the contract. In Sequence 14, M vocalizes as K says "There" at 01:57. He follows this with another vocalization as he maintains his left hand on the zipper and loosely moves his right hand along the right side of his body.

In Sequence 15 (01:58 - 02:04), M asserts his 'next thing' agenda first with forceful audible OUTBREATHS (01:58 and 01:59) followed by panting accompanied by movement of hands (02:00) and culminating in his second leg lift-pointing gesture beginning at 02:01 and maintained to 02:03. This also precedes the concluding recycling Sequences (16 - 22) during which $\mathrm{M}$ is self-addressed and without $\mathrm{K}$ as partner. It is possible that $\mathrm{M}$ is reassured with K's activity across the room that the 'next thing' transition is on its way, and is thus able to return to his own thoughts about the zipper sequences in the remainder of the film.

Summary of 'agenda' management as pattern of emotional investment. The patterns of alignment, and the points at which M's challenges to alignment and several natural obstructive "surprise" events (the too-tight t-shirt neck over his mouth, head dropped on table, zipper sticking) threaten the smooth pursuing of K's teaching/changing agendas, mark the shifting stance of $M$ in relation to $K$ and the action, as well as of $K$ in relation to $M$ and her agenda-management. Importantly, non-alignment leading to agenda dissolution never quite "breaks out"; they remain synchronized in a dance-like interaction through K's efforts to reengage M's interest and M's apparent though conditional acceptance of waiting at each transition and his "agreement" to go along with the action controlled by K. M waits to see if anything interesting does come up after K redirects his attention (he also employs 'raspberry' sound and 'clicking' to regulate his impatience for 'next thing'). He is, however "on point" 
throughout, never letting go of his 'next thing' agenda, raising this 'topic' through 'impatient' manner at transitional points. His ability to focus on several things at once as well as strong emotional engagement in these several things, even though they point in different directions is also clear.

\section{Recycling with Difference/Variation: Creative (Cognitive) Use of Prior Elements and Production of Expressions with Linguistic Quality in Exploring the Theme of 'Fastening'}

$\mathrm{K}$ employs a conversational frame through "conversation" hands, positioning $\mathrm{M}$ as speaker then adjusting her grip to place him as doer of something of which he is not physically capable (doing up the zipper). This is part of the frame $\mathrm{K}$ is constructing and which $\mathrm{M}$ later reuses in his recyclings and is part of a construction of alignment. As the teacher, she is engaged in the construction of co-construction (showing co-construction) through listening and speaking. Her "listening" hands also initially position $\mathrm{M}$ as the speaker, then a slight shift in position maintains him as 'speaker' while his hands are also manipulated into doing the action being spoken about. The two positions are thus "made comparable" - speaking and doing up the zipper are actions and he is positioned as "doing" both. $\mathrm{K}$ is less involved in the 'co-' project as a whole and more concerned with underscoring M's status and agency as "first person", acting as if he is doing all this for himself. It is significant that the high point of M's "doing" occurs in Sequence 10, and that this sequence appears to provide the source material for the majority of M's rhematic expressions as shown in Table 1.

Sequences 16 - 22 (02:05 - 02:22) are each between 1 - 3 seconds in length and feature $\mathrm{M}$ in conversation with himself as he recycles elements of the previous talking about and doing up of the zipper on the bathing suit. He produces gentle 'clicking' sounds throughout. M's recycling sequences can be seen to concern the theme of 'fastening' / 'fastened', developed through the rhematic expressions he recycles and constructs. He begins in Sequence 16 by making what could be the formal negotiated sign for BATHE/SWIM (as he stays at chest level in keeping with this sign). However, this movement also partially recycles the source $\rightarrow$ goal frame used by $\mathrm{K}$ to introduce the zipper on the suit beginning in Sequence 3, and is followed by successful recycling rounds of this frame within which he employs rhemes, new rhemes and rhemes with variation (Anward, 2004). 'Zipper' manner is a rheme introduced by K within the "exemplar turn" (Anward, 2004, p. 1) of the source-path-goal frame within which $\mathrm{K}$ casts the conversation about, and doing-up of, the zipper. $\mathrm{M}$ is showing re-use of the (linguistic) frame in speaking with himself. The grammar of the frame (including the S-P-G metaphor) has given him something to work with through which he can perceive and play with new details. $\mathrm{M}$ can be seen to be doing a form of exploration (perceptuo-cognitivelinguistic) at an abstract level; that is, exploring an emerging concept of fastening.

According to Anward (2004) in recycling with differance, a new rheme signals a new contribution ('zipper' sound manner from 'velcro' sound manner); a repeated or retained 


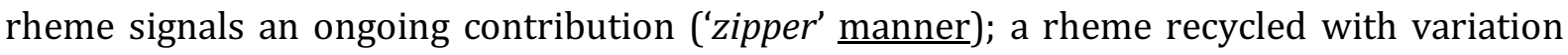
seems to signal a new formulation of a previous contribution ('zipper teeth' manner 'fastenedup-here-chin' manner, 'zipper tab in pocket' manner). Through employing prior elements, $\mathrm{M}$ scaffolds his own exploration through recycling the original frame and achieves greater complexity than that shown in the original frame within his recycling rounds of it.

Below is a table identifying rhematic expressions employed by M in his recyclings, their nature, location and possible origin in the prior interaction.

\section{Table 1}

Summary of rhematic expressions (R), rhematic expressions $w /$ variation $(R w V)$, and new rhematic expressions (NR) located within the recycling sequences (S16 - S22) M, with proposed origins (S1 - S15)

\begin{tabular}{|c|c|c|c|}
\hline$R / R \mathbf{w} V / N R$ & Description & Location & Origins \\
\hline NR & 'zipper sound' $\underline{\text { manner }}$ & S10: $01: 27.8$ & $\begin{array}{l}\text { S10: 01:23 - 01:24; } \\
\text { 'Velcro sound' manner }\end{array}$ \\
\hline $\mathrm{R}$ & $\begin{array}{l}\text { 'zipper' manner on } \\
\text { place }\end{array}$ & S16: 02:05.0 - 02:06.1 & $\begin{array}{l}\text { S3: } 00: 36-00: 37 ; \text { S4: 00:39, } \\
\text { 00:40 - 00:41; S9: 01:15 - } \\
\text { 01:16; S10: 01:18-01:30; S11: } \\
\text { 01:31 - 01:33 }\end{array}$ \\
\hline $\mathrm{R}$ & $\begin{array}{l}\text { 'zipper' manner on } \\
\text { place }\end{array}$ & S17: 02:06.1 - 02:06.9 & ----“------- \\
\hline $\mathrm{R}$ & $\begin{array}{l}\text { 'fastening zipper' } \\
\underline{\text { manner on place }}\end{array}$ & S17: 02:07.0 - 02.07.3 & S10: 01:23 - 01:30 \\
\hline NR & $\begin{array}{l}\text { 'partially closed } \\
\text { zipper-open neck suit' } \\
\underline{\text { manner on place }}\end{array}$ & S17: 02:07.0 - 02:08.0 & S10: 01:28 - 01:30 \\
\hline NR & $\begin{array}{l}\text { '(closed }) \text { zipper teeth' } \\
\text { manner on place }\end{array}$ & S17: 02:07.4 - 02:08.5 & $\begin{array}{l}\text { S5: 00:44 - 00:54 S10: 01:17 - } \\
01: 30\end{array}$ \\
\hline $\mathrm{R}$ & $\begin{array}{l}\text { 'zipper' manner on } \\
\text { place }\end{array}$ & S18: 02:09.0 - 02:11.0 & \\
\hline
\end{tabular}




\begin{tabular}{|c|c|c|c|}
\hline $\mathrm{R} w \mathrm{~V}$ & $\begin{array}{l}\text { 'zipper (with thumbs } \\
\text { touching)' manner on } \\
\text { place }\end{array}$ & S19: $02: 13.0-02: 13.2$ & S10 : 01:29 - S11: 01:32 \\
\hline Rw V & $\begin{array}{l}\text { 'zipping all the way up } \\
\text { at once' manner on } \\
\text { place }\end{array}$ & S19: 02:13.0 - 02:14.0 & S10: 01:24-01:30 \\
\hline $\mathrm{R}$ & $\begin{array}{l}\text { 'zipper' manner on } \\
\text { place with }\end{array}$ & S20: 02:14.0 - 02:15.0 & \\
\hline $\mathrm{R}$ & $\begin{array}{l}\text { 'fastened' manner on } \\
\text { place with }\end{array}$ & S20: $02: 14.5-02: 15.5$ & S10: 01:30 \\
\hline NR & $\begin{array}{l}\text { 'closed zipper teeth' } \\
\text { manner on place }\end{array}$ & S20: 02:14.0 - 02:15.8 & S10: 01:17 - 01:30 \\
\hline NR & $\begin{array}{l}\text { 'zipper } t a b \text { ' manner on } \\
\text { place }\end{array}$ & S21: $02: 15.3-02: 16.7$ & S9: 01:16; S10: 01:19- 01:24 \\
\hline NR & $\begin{array}{l}\text { 'pocket' manner on } \\
\text { place }\end{array}$ & S21: 02:16.7 - 02:17.2 & S10: 01:30; S13: 01:53 - 01:57 \\
\hline $\mathrm{Rw} \mathrm{V}$ & $\begin{array}{l}\text { 'zipper tab in pocket' } \\
\text { manner on place }\end{array}$ & S21: $02: 17.2-02: 19.0$ & S10: $01: 30$ \\
\hline $\mathrm{R}$ & $\begin{array}{l}\text { 'pushing tab into } \\
\text { pocket' manner on } \\
\text { place }\end{array}$ & S22: 02:19.0 - 02:19.4 & S10: 01:30 \\
\hline $\mathrm{R}$ & $\begin{array}{l}\text { 'fastening' / 'fastened' } \\
\text { manner on place }\end{array}$ & S22: 02:19.1 - 02:19.4 & S10: $01: 30$ \\
\hline $\mathrm{R} w \mathrm{~V}$ & $\begin{array}{l}\text { 'Fastened all the way } \\
\text { up to here (chin)' } \\
\text { manner on place }\end{array}$ & $\begin{array}{ll}\text { S:22: } & 02: 19.5 \quad- \\
02: 23.3 & \end{array}$ & S10: $01: 30$ \\
\hline
\end{tabular}




\section{Summary of the Results of the Rhematic Analysis}

In total, there are 18 instances of rhematic production from S16 02:05 - S22: 02:22. There are 12 distinct rhematic expressions (in the interest of brevity, these will be referred to as "rhemes" in the sense of content or keywords). There are 6 new rhemes and 4 rhemes with variation, and 3 previously introduced rhemes reused by M. In keeping with the conditions of recycling as defined by Anward (2004), most of the instances in which $\mathrm{M}$ re-uses a prior rheme ('zipper' manner on place) have to do with his recycling of the S-P-G mini-frame used by $\mathrm{K}$ to show 'zipper' manner and to frame the talk about and doing up of the zipper. $\mathrm{K}$ has also recycled this rheme several times prior to a shift to talk about the shower (their next context). M begins his recycling sequences with this frame and applies 'zipper' manner four times. His fluid joining of 'zipper' manner with the old rheme of 'fastened' manner and then the new rheme 'closed zipper teeth' manner is an additional instance of creativity in terms of the production of a new linguistic construction. Here he has effectively both produced his own new rheme at the same time as he recycles the two prior rhemes to produce the new construction. The overwhelming majority of the rhematic expressions themselves are either entirely new or involve variation, and just over half of all the rhematic production as a whole is of new rhemes or of rhemes with variation. This result provides support for the definition of recycling (above) applied here, as necessarily involving novel creation / variation through re-use of prior linguistic material. It also presents a compelling picture of M's creativity and perceptuo-cognitive-linguistic skill.

S10, and in particular one specific point within it (01:30) is identified as the source for most of the rhematic production (see table above). There is a likely bodily emotional trace (Daelman et al., 2001) or BET produced by K's hand touching M's chin after they have both pulled the zipper tab up, and an impression as she also pushes her finger into the zipper pocket directly afterward. M's right hand has followed as the two sides of the suit are drawn together toward the culminating point and he has felt the progress of the zipper as the two sides of the suit are transformed into one. This highly tactile, multi-focused and culminating episode (reaching 'goal' place within the S-P-G frame - the conversational "high point") is seen again in the nature of M's rhematic expression. The richness of this high point, both tactile and in terms of multiple points of focus, is likely to be the reason for its overrepresentation as source material for the production of rhematic expressions.

\section{Conclusion: Recycling with Variation as Dialogical Syntax}

According to dialogical grammar, conversational turns and their component units have systematic relations to their sequential context (Linell, 2002). That M makes good use of the Source-Path-Goal metaphor mini-frame suggests both his grasping of this 'exemplar turn' and suggests the usefulness of the technique of 'format tying', tying a turn to the action of the previous speaker and to the wording of the previous speaker (Goodwin \& Goodwin, 1987). 
This is an aspect of the interactive method by which language emerges; a method for doing interaction (Anward, 2004). The creativity involved in M's rhematic production within the exemplar turn is also cognitively significant. $\mathrm{M}$ is showing aspects of cognition that could easily be called working memory, creativity and abstract thinking (viewed as his elaboration of the conceptual-linguistic frame through construction of new details within it) that are central topics in the assessment of cognition. He is also showing appropriation (Dufva, Aro, \& Suni, 2014) and creation of language through the strategy/strategic resource of recycling (Anward, 2004; Perkins, 2014).

Dialogical syntax (Du Bois, 2007, 2010) is a newer theory within cognitive-functional linguistics that studies the linguistic, cognitive and interactional processes involved when users of language "reproduce selected aspects of a prior utterance, and when recipients respond to the parallelisms and resonances that result, drawing inferences for situated meaning" (Du Bois \& Giora, 2014, p. 352). Parallelism is a relation of structural similarity between two or more stretches of discourse that serves the interactional and dialogical purposes of speakers in speaking (Du Bois \& Giora, 2014; Anward, 2014). Resonance relates more closely to notions of 'engagement', and arises from utterances being brought into relation to one another, which defines a "matrix of affinities" (Du Bois, 2010, p. 3) or, more dynamically, the "catalytic activation of affinities across utterances" (Du Bois \& Giora, 2014, p. 351). These affinities, a) may be based on similarity, but also on difference (p. 353), b) are the 'currency' of dialogic connection, (Du Bois, 2007), the source and also the product of structuring engagement between juxtaposed utterances (Du Bois, 2010), c) can be systemic in the sense of being based on stable linguistic properties found within a single linguistic community, d) but also constructed "on the fly in ways that may be comprehensible only to those who were present in the dialogic moment" (Du Bois \& Giora, 2014, p. 353). Anward (2014) points out that his "recycling with difference" is a type of turn that others have variously referred to as format tying, repetition and quotation, and as resonance (citing $\mathrm{Du}$ Bois, 1996, p. 1).

Importantly, dialogic syntax is not restricted to conversational interaction but can also be found in the successive clause construction of a single speaker (Du Bois, 2010). It is not about repetition or agreement per se, but rather an engagement with the words of the previous speaker and it establishes relations that have an impact on meaning in the moment (Du Bois, 2010). In this way, it highlights the significance of the spoken way of creating language, a point that fits well with the pragmatic and enactive accounts of embodied cognition and communication described earlier, and with the appropriation account of language practice rather than language acquisition (Dufva, Aro \& Suni, 2014). It is cognitively significant also because it is an attempt to observe, describe and theorize abstraction in process, in the context of the dialogic moment (Du Bois, 2010). It is argued here that $\mathrm{M}$ is engaged in such a process of abstraction, or cognition at the level of reflection, in which elements are 
distinguished with the help of language elements, reexamined and reconstituted as new objects of consciousness (Merleau-Ponty, 1962). It is maintained here that the case described above provides a clear and detailed example of dialogic syntax serving the intention of cognitive reflection through recycling with differance or variation. 


\section{References}

Anward, J. (2004). Lexeme recycled: how categories emerge from interaction. Logos and Language, 2, 31-46.

Anward, J. (2014). Interaction and constructions. Constructions. 1-2/2014 http://elanguage.net/journals/constructions, 1-7.

Arbib, M. (2008). From grasp to language: Embodied concepts and the challenge of abstraction. Journal of Physiology-Paris, 102, 4-20.

Aziz-Zadeh, L., \& Damasio, A. (2008) Embodied semantics for actions: findings from functional brain imaging, Journal of Physiology-Paris, doi: 10.1016/j.jphysparis.2008.03.012.

Barsalou, L.W. (1999). Perceptual symbol systems. Behavioral and Brain Sciences, 22, 577660.

Barsalou, L. W., Simmons, W. K., Barbey, A. K., \& Wilson, C. D. (2003). Grounding conceptual knowledge in quality-specific systems. Trends in Cognitive Sciences, 7, 84-91.

Berman, R. Ragnarsdottir, H., \& Stromqvist, S. (2002). Discourse stance. Written languages and literacy, 5, 253-287.

Biber, D., \& Finegan, E. (1989). Styles of stance in English: lexical and grammatical marking of evidentiality and affect. Text-interdisciplinary Journal for the Study of Discourse, 9, 93-124.

Brentano, B. (1874/1973). Psychology from an empirical standpoint. A. C. Rancurello, D. B. Terrell and L. L. McAlister (Trans.). London: Routledge and Kegan Paul.

Chafe, W. (1994). Discourse, consciousness, and time: the flow of language in speech and writing. Chicago: Chicago University Press.

Clark, A., \& Chalmers, D. (1998). The extended mind. analysis, 58(1), 7-19.

Corbin, J., \& Strauss, A. (2015). Basics of qualitative research: techniques and procedures for developing grounded theory, (4. Ed.). Los Angeles: Sage.

Derrida, J. (1981). Positions. Chicago: The University of Chicago Press.

Du Bois, J. W. (1996). Dialogic syntax. Paper presented at the $5^{\text {th }}$ International Pragmatics Conference. Mexico City, Mexico, July 1996.

Du Bois, J. W. (2007). The stance triangle. In R. Englebretson (Ed.), Stancetaking in discourse: Subjectivity, evaluation, interaction (pp. 139-182). Amsterdam: Benjamins.

Du Bois, J. W. (2010). Towards a dialogic syntax. Draft article. (Ref.: Du Bois, J. W. (2014). Cognitive Linguistics, 25, 359-410).

Du Bois, J. W., \& Giora, R. (2014). From cognitive-functional linguistics to dialogic syntax. Cognitive Linguistics, 25(3), 351-357. 
Du Bois, J.W., Hobson, R.P. \& Hobson, J.A. (2014). Dialogic resonance and intersubjective engagement in autism. Cognitive Linguistics, 25(3): 411-441.

Dufva, H., Aro, M., \& Suni, M. (2014). Language learning as appropriation: how linguistic resources are recycled and regenerated. In P. M. Litunen, S. Peltola \& M.-L-. Varila (Eds.), AFinLA-e Soveltavan Kielitieteen Tutkimuksia 2014/n:o 6, 20-31.

Forsgren, G.A.G.C., (2018). Sign Construction Based on Heightened Tactile Perception by Persons with Congenital Deafblindness. Journal of Deafblind Studies on Communication, 4, 4-23.

Gallagher, S. (2005). How the body shapes the mind. Oxford: Clarendon Press.

Gallagher, S. (2011). Interpretations of embodied cognition. In W. Tschacher \& C. Bergomi (Eds.), The implications of embodiment: cognition and communication (pp. 59-71). Exeter: Imprint Academic.

Gallagher, S., \& Zahavi, D. (2008). The phenomenological mind: an introduction to philosophy of mind and cognitive science. London: Routledge.

Gallese, V., \& Lakoff, G. (2005). The brain's concepts: The role of the sensory-motor system in conceptual knowledge. Cognitive Neuropsychology, 22 (3/4), 455-479.

Glaser, B. G., \& Strauss, A. L. (1967). The discovery of grounded theory: Strategies for qualitative research. New York: Aldine De Gruyter.

Glenberg, A. M. (2008). Toward the integration of bodily states, language and action. In G. R. Semin \& E. R. Smith (Eds.), Embodied grounding: social, cognitive, affective and neuroscientific approaches (pp. 43-70). Cambridge: Cambridge University Press.

Goodwin, M. H., \& Goodwin, C. (1987). Children's arguing. In S. Philips, S. Steele and C. Tanz (Eds.), Language, gender, and sex in a comparative perspective, pp. 200-248. Cambridge: Cambridge University Press.

Hoffman, M., \& Pfeifer, R. (2011). The implications of embodiment for behavior and cognition: animal and robotic case studies. In W. Tschacher \& C. Bergomi (Eds.), The implications of embodiment: cognition and communication (pp. 31-58). Exeter, UK: Imprint Academic.

Johnson, M. (1987). The body in the mind: the bodily basis of meaning, imagination, and reason. Chicago: The University of Chicago Press.

Kaschak, M. P., \& Glenberg, A. M. (2000). Constructing meaning: The role of affordances and grammatical constructions in sentence comprehension. Journal of Memory and Language, $43,508-529$.

Lakoff, G., \& Johnson, M. (1980). Metaphors we live by. Chicago: University of Chicago Press. Linell, P. (2002). En dialogisk grammatik? http://www.nordis-ka.uu.se/samtal/index.html 
Linell, P. (2009). Rethinking language, mind and world dialogically: interactional and contextual theories of human sense-making. Charlotte, NC: IAP

Linell, P. (2010). Dialogicality and language. Paper delivered March 2010, R.U. Groningen, The Netherlands (DBI conference).

Markova, I. (2003). Validation and generalization using single case studies: a dialogical approach. Paper presentation, University of Stirling.

Markova, I. (2006). On 'the inner alter' in dialogue. International Journal for Dialogical Science, $1,125-147$.

Merleau-Ponty, M. (1962). Phenomenology of perception. C. Smith (Trans.). London: Routledge \& Kegan Paul.

Ochs, E. (1996). Linguistic resources for socializing humanity. In J. J. Gumperz and S. C. Levinson (Eds.), Rethinking linguistic relativity (pp. 407-437). Cambridge: Cambridge University Press.

Perkins, M. R. (2014). Linguistic recycling in typical and atypical interaction. Clinical Linguistics and Phonetics, 28(7-8): 590-601.

Pickering, M. J., \& Ferreira, V. S. (2008). Structural priming: a critical review. Psychological Bulletin, 134, 427-459.

Pickering, M. J., \& Garrod, S. (2004). Toward a mechanistic psychology of dialogue. Behavioral and Brain Sciences, 27, 169-226.

Suni, M. (2008). Toista kielta vuorovaikutuksessa: kielellisten resurssien jakaminen toisen kielen omaksumisen alkuvaiheessa. Jyvaskyla Studies in Humanities 94. Jyvaskyla: University of Jyvaskyla.

Tannen, D. (1985). Relative focus on involvement in oral and written discourse. In R. Olson et al. (Eds.) Literacy, language and learning (pp. 124-147). Cambridge: Cambridge University Press.

Thompson, E., \& Varela, F. J. (2001). Radical embodiment: neural dynamics and consciousness. Trends in Cognitive Sciences, 5(10), 418-425.

Trevarthen, C. B. (1979). Communication and cooperation in early infancy: A description of primary intersubjectivity. In M. Bullowa (Ed.), Before speech. Cambridge: Cambridge University Press.

Van Lier, L. (2007). Action-based teaching, autonomy and identity. Innovation in Language Learning and Teaching, 1 (1), 46-65. 
Kirsten Costain, Senior Adviser, Unit for dual visual and hearing loss and deafblindness, Statped southeast, Norway; e-mail: <Kirsten.Costain@statped.no>. Jacques Souriau, Psychologist, Lecturer, Department of Special Needs Education and Youth Care, Rijksuniversiteit Groningen, Netherlands; $e^{-}$mail: <Jacques.souriau@gmail.com>. Marlene Daelman, Educational Psychologist, MFC De Kade-Spermalie, Belgium; Lecturer, Department of Special Needs Education and Youth Care, University of Groningen; email: <marlene.daelman@skynet.be>. 